\title{
INERCIAS Y TRANSFORMACIONES EN LAS RELACIONES LABORALES DEL URUGUAY
}

\author{
FramisoPuci*
}

\section{INTRODUCCIÓN}

En numerosos ámbitos académicosy políticos, se ha planteado la idea de que las transformaciones que se producen en el ámbito laboral obedecen a la aplicación de políticas de corte neo-liberal, en el marco de los procesos de gl obalización quesedesarrollan a escala mundial. Si bien esta afirmación es cierta, en la medida en quela reestructuración productiva denumerosos países de América Latina, entreellos Uruguay, se real izó, en el marco de procesos deintegración re gional, inspirados en la filosofía neo-liberal, también es cierto que las transformaciones en el mundo del trabajo quese producen en estos paísesnosepueden remitirúnicamentealaaplicación de un modelo económico o social específico de desarrollo. Las mismas están inscriptas en modificaciones estructurales de largo plazo,

* Professor-Doutor da Faculdade de Ciências Sociais e da Faculdade de Direito da Universidade da República Oriental do Uruguai (UDELAR). Constituyente 1502, Piso 5, Cep: 11.200, Montevideo, Uruguay. pucci@fcs.edu.uy asociadas a los cambios en el mundo del trabajo que se producen a escala internacional y que trascienden laaplicación deunapolíticaeconómica determinada o un marco político o ideológico específico, constituyéndoseen transformacionesprofundas y duraderas de la sociedad. Partiendo de estas premisas, consideramos quecual quier política dedesarrollo queseinscriba en orientaciones económicas, políticaso ideológicas diferentesalas queseimplementan en laactual idad debeasumir la presenciaeirreversibilidad deestasnuevas realidades productivas.

Otro aspecto quedebemos señalar es quela globalización no opera como causa de los fenómenos de transformación de los procesos productivos, sino que constituye un nuevo escenario quemodifica los datos del contexto, sin necesariamente constituirse en la variable explicativa fundamental. En medios políticos y académicos, existe una tendencia a explicar los procesos decambio en la organización productiva y en la acción sindical, así como la orientación, dirección eimplementación de las políticas y los procesos de reforma laboral, como consecuencia 
del fenómeno dela gl obalización, aunque sólo en escasas ocasi ones la rel ación de causa-efecto aparece debidamente especificada y justificada. En numerosas ocasiones, no seestableceel nexo causal que se implica ni se contempla la posibilidad de que los impactos esgrimidos pudieran tener orígenes, causas, razones o motivos más cercanos quelosexplicaran mejor. Lamayoríadelos estudios y ensayos atribuyea la gl obalización una serie de impactos queexageran sus efectos o queatribuyen a la gl obal ización ser la causa inmediata de una variedad de consecuencias en el campo laboral, cuando formar parte del escenario no implica necesariamenteser la causa del fenómeno.

Sal vando estas consideraciones preliminares, coincidimos con la idea de que la impronta neo-liberal en que desarrollaron los procesos de integración regional y las políticas laborales delos años 90 tuvieron impactos profundos en los actores laboralesy los marcos institucionales en los cuales los mismos desplegaron su accionar. En este sentido, el trabajo seproponeanalizar la evolución de las relaciones laborales en el Uruguay, desde el advenimiento democrático ocurrido en 1985 hasta nuestros días, desde una triple vertiente: los cambios productivos, Ia evolución delanegociación colectivay las transformacionesen el movimiento sindical en tanto actor social. Previo a ello, realizaremos un breve análisis de los principal es rasgos quedefinen el proceso deintegración regional que seinicia en los años 90, en la medida en queestos procesos han tenido consecuencias importantes para las relaciones laborales y para el mundo del trabajo en un pequeño país como Uruguay, para el cual el significado que ha tenido la participación en mercados regionales adquiere características específicas.

\section{LA CONFORMACIÓN DEL MERCOSUR}

Una de las características que distinguee proceso de integración regional que comenzó a gestarse en los últimos años, culminando con la firma del Tratado de Asunción entre Argentina,
Brasil, Uruguay y Paraguay, MERCOSUR, es que seoriginaen el marco deuna propuestaeconómica y social decortefuertementeneoliberal. Esto leda al mismo una singularidad quelo aparta decididamente de experiencias de integración regional desarrolladas en otros contextos.

Sobrela basedeexplotar las "ventajas comparativas" delosdistintos paísesanivel internacional, sellevóa cabo unareconversión delaeconomía y una apertura irrestricta al mercado externo, todo ello bajo el esquema monetarista. La denominada exportación no tradicional creciónotablemente, en basea la política desubsidios oficiales (entreotros factores), a la vez que parte de las industrias nacionales, consolidadas en el período de "sustitución deimportaciones", experimentaron una violenta reversión (Argenti, 1989).

En este marco, se crearon asimismo condiciones excepcionales para la incorporación de equipos y tecnología, especialmente en las industrias de exportación. Los incentivos económicos a estas actividades, la caída de los aranceles, la sobrevaluación de la moneda y la afluenciadepréstamosinternacionalesfavorecieron el reequipamiento industrial del período.

En el caso uruguayo, hasta 1974 d desarrollo industrial del país estuvo enmarcado en las pautasquecaracterizaron al llamado período sustitutivo de importaciones: industrias protegidas por la acción estatal y orientadas haciael mercado interno. Este periodo tuvo su máxima expansión entre los años 1930 y 1958, aunque antes de 1930 Uruguay había conocido un relativo desarrollo industrial. Luego de 1974, la política económica se orientó a la apertura de la economía y al desarrollo de una industria de exportación de productos no tradicionales, en el marco de una doctrina neoli iberal en lo económico. Si bien en la década del 70 laeconomía uruguayalogra salir del estancamiento delos sesenta, ello no significó un mejoramiento equival ente en las condiciones de vida de la población. La crisis de los 80 aumentó estos aspectos negativos. La recuperación que se logratras el retorno dela democracia permite, junto con el crecimiento del producto, una mejoraen 
Iosniveles desalario, como en latasa dedesempleo, quesereduce a $9 \%$, al tiempo quela distribución del ingreso tuvo una leve mejoría.

Lanecesidad decompetir con los productos extranjeros, no sól o en los mercados externos, sino también en el propio mercado interno, introdujo cambios en el funcionamiento de las actividades productivas en todas las ramas. La expansión exportadora fue acompañada de un cambio en los mercados de destino de nuestras ventas. Argentinay Brasil pasan a ser los socios comerciales más importantes del Uruguay, al canzando, en al gunos años, a comprar en conjunto, un $30 \%$ del total de exportaciones.

Lainnovación tecnológicay los cambiosen los procesos productivos aparecen como condiciones necesarias para una mejor inserción de las exportaciones en los mercados internacionales. A nivel delaindustria seconstata, a partir de 1974, una fuerterenovación de maquinariay equipamiento en las empresas demayor envergadura económica, tanto en aquellas quehan desarrollado estrategias de exportación como en aquellas que mantienen fuertes vínculos con el mercado local. Esteproceso deinnovación técnica incluyó cierta incorporación de componentes microelectrónicos, aunque sin alcanzar a constituir procesos automatizados de producción, según los parámetros del mundo desarrollado.

Los procesos de transformación de la industria uruguaya, al igual que otros contextos industriales latinoamericanos, se pueden explicar através del concepto de "hibridización" (Novick et al., 2002). Esta perspectiva partedela base deque existeuna interacción compleja entre los modelos deorganización del trabajo, las decisiones estratégicas delos núcl eos empresariales o delas autoridades jerárquicas y los contextos nacionales e institucionales en los cuales seimplementan estos procesos. El resultado es que las formas de organización del trabajo tienden a asumir formas "híbridas", en las cuales se yuxtaponen y se entremezclan componentes dediferentes modelos, sobrela basedelatransformación oredefinición de los equival entes funcionales del model o deorigen.
La globalización es el contexto a través del cual se difunden las herramientas de gestión (calidad total, re-ingeniería, etc.) en el mundo del trabajo. En este plano, muchas de las nuevas formas deorganización del trabajo implementadasen nuestros países no asumen la lógica integral delos nuevos modelos productivos, sino aspectos parcialesy fragmentarios delosmismos. Otrocomponente importante de estos procesos es que, en numerosas ocasiones, el modelo original detrabajo tieneunafuerzaemblemática quepermeatodas las futuras transformaciones que se dan en la organización dela empresa o del servicio (Pucci; Bianchi, 2006).

Como se señaló en trabajos anteriores (Supervielle; Pucci, 1991), en el caso uruguayo, la incorporación y adaptación denuevasherramientas de gestión se real iza en un contexto industrial de tipo patrimonial, donde predominan vínculos de tipo paternal ista y particularista que permean todas las relaciones sociales de tipo fabril. Lejos de sustentarseen criterios abstractos eimpersonales de logro, eficiencia y competitividad, al estilo de las grandes empresas del mundo desarrollado, las relaciones sociales, en las empresas capitalistas uruguayas, están teñidas de "familismo" y lealtades personales. Estos particularismos atraviesan la organización productiva, de la cual no se puede decir que siga estrictamente los criterios de tipo taylorista fordista, expuestos más arriba. Por otra parte, laimposición deesta forma deorganización laboral depende, paracada sociedad, eincluso para cada empresa, de los niveles de organización y lucha alcanzados por los sindicatos obreros. De al guna manera, todo proceso de trabajo presupone la cristal ización de una serie de componentes de tipo social y político, quevarían decaso en caso y que resultan de la confrontación de diversas tendencias.

En ese sentido, la organización del trabajo tradicional en la industria uruguaya, si bien se inspira en los métodos y las concepciones tayloristas-fordistas, lo hace demanera más atenuada en cuanto a sus efectos, que lo que ha sido en otros contextos. Es en este contexto productivo 
donde se realiza la incorporación de modernos instrumentos de gestión (calidad total, reingeniería, etc.), quetienen efectos variados según ramas o sectores de actividad (Supervielle; Quiñones, 1999). Sin embargo, pese a la heterogeneidad delas situaciones, podemos concluir que las estrategias de modernización productiva ensayadas por los empresarios, en los últimos años, parecen priorizar laflexibilidad externa (flexibilización de las condiciones contractuales de trabajo) más que la flexibilidad funcional (polival encia del desempeño laboral al interior dela empresa), aunquela matriz histórica de las relaciones laborales y la acción del movimientosindical han dismi nuido relativamente la primer tendencia. Su consecuencia parece ser un crecienteproceso dedesregulación (Supervielle; Pucci, 1995), expresada en el predominio derelaciones informales entre los actores laborales. De todas maneras, tanto a nivel dela industria como anivel delos servicios, las estrategias empresariales priorizan la reducción decostos, víaflexibilización de las condiciones contractuales de la mano de obra o la tercerización de partes del proceso productivo, más quela apuesta a una mejora en el desempeñolaboral dela empresa.

\section{LANEGOCIACIÓN COLECTIVA ${ }^{1}$}

Los cambios productivos modificaron las condiciones y modalidades de la negociación colectiva. La "ecuación keynesiana”, basada en la negociación centralizada y formalizada-en lacual intervienen sindicatos que nuclean grandes contingentes de trabajadores y en la cual el Estado tieneunaintervención activa en laformulación de leyes laboral es y en el respaldo a la negociación es considerada, por los propulsores de estas estrategias dedesarrollo, como inadecuadaal nuevo contexto productivo. Las nuevas tendencias apuntan a un retiro del Estado como árbitro dela negociación, reduciéndola a la instancia bi lateral;

${ }^{1}$ Parte de esta discusión fue publicada en Pucci, 2006.
Ios convenios por empresa adquieren mayor centralidad quelos convenios por rama, y las líneas de negociación se amplían y se complejizan. La pérdida decentral idad dela acción sindical tiende a fragmentar la negociación, que se define según clivajes detipo corporativo más quedetipo ideológico-programático, a despolitizar la función sindical y a disminuir el peso de las adscripciones partidarias (Pucci, 2003).

Estos elementos se plantean como tendencias generales dela reestructuración capitalista, aunque su resolución concreta depende de diversos factores. En particular, delas inserciones nacionales de los movimientos sindicales en el sistema político, desu mayor o menor autonomía frenteal Estadoy del mayor o menor componente corporativo o plural ista en la estructuración delas relaciones de trabajo, en cada caso. Para el caso uruguayo, el modelo de relaciones laborales se puedecatal ogar como "corporativismo subordinado" (Lanzaro, 1992) en el cual, más allá de los espacios formalizados de intermediación de intereses (Consejos deSal arios, Comisiones, etc.), el accionar de los partidos políticos tuvo una importancia considerable, para garantizar el funcionamiento delos organismos denegociación y garantizar la estabilidad de los acuerdos. El debilitamiento de las estructuras partidarias ocurrido en los últimos años no sólo debilita al movimiento sindical, sino quetambién fragilizalas arenas deintermediación deintereses construidas históricamente

Tomando como punto de partida del análisis, la política de relaciones laborales implementada por el primer gobierno colorado, que asumeentre 1985 y 1989, luego del período militar, vemosquela mi sma resultó una combinación deelementosjurídicos provenientes del Estado de Bienestar de la década de los 40 , con elementos fuertementecentralizadores dela etapa autoritaria defines del 70. Estemodelo intentó compatibilizar una políticaeconómica anti-inflacionaria, deajuste y control del gasto público con un sistema de negociación, en el cual serecuperaran dinámicas y procedimientos de participación laboral 
prevalecientes en el período anterior al golpe de Estado. Partiendo deestas premisas, la negociación salarial se desarrolló en forma centralizada, con unafuerteparticipación estatal, demanera demarcar límites a los acuerdos salariales, para que no se tradujeran en inflación, al tiempo que se respetaba la decisión de las partes cuando el aumento superaba los topes oficiales (Pucci, 1992).

La administración blanca, que asume en 1990, impondrá una política de desregulación y de apertura de la economía. La firma del Tratado deAsunción aparececomo hito descollantedeuna nueva actitud de desmontaje delas subvenciones y del proteccionismo estatal como orientación del Estado en el proceso de integración regional. El Estado se retira de la negociación salarial, reduciéndola a la instancia bilateral, e intenta, aunque sin éxito, reglamentar directamente la actividad sindical. Es la contracara del viejo Estado batllista idem, sólo pocas líneas o un § para explicar que intervenía como árbitro en las negociaciones, pero que otorgaba autonomía organizativa a los sindicatos. Esta orientación se da en un contexto de fuerte debilidad del movimientosindical, queseempezó asentir apartir de 1988y queseacentuó con la crisis del socialismo real a partir de los 90 .

La propuesta del gobierno blanco impulsó la "desregulación" de las relaciones laborales, teniendo como objetivo darleunamayor flexibilidad ala contratación y laorganización dela producción, adecuar lasmismasalas necesidades deinnovación tecnológica y reconversión productiva y quitarle el ementos de garantía y protección de los trabajadores, considerados como "obstáculos" auna mejor inserción de la economía en los mercados externos y en los acuerdos de integración regional. Esta propuesta se asoció a la concepción de queel Estado no debía intervenir en los conflictos entrecapital y trabajo, los cuales sedebían procesar en la esfera privada por acuerdos bilaterales a nivel de empresa. A su vez, la desarticulación de las arenas de intermediación de intereses implementadas por el gobierno colorado amenazó con fortalecer una lógica de confrontación en desmedro deuna práctica denegociación retomada y profundizada desde la instauración de la nuevainstitucional idad democrática.

La consecuencia lógica de esta política laboral fuelacrecientepolarización entrecapital y trabajo, una agudización dela conflictividad a niveles similares a los del período de transición y un fuerte descenso en el nivel de ingresos, en el corto plazo, paralos trabajadores. Estaorientación fragmentóla negociación col ectiva, quitó espacios ala acción sindical centralizada con fuertepresencia pública, acotó la "Iucha de clases" a la esfera privaday tendió a despolitizar, en un sentido profundo, al movimiento obrero. A su vez, esta política coincidió con un período de debilidad del movimiento sindical, expresado en una baja capacidad de convocatoria y un descenso de su "peso estructural" en la economía uruguaya.

En materia salarial, la política ensayada en el nuevo modelo consistió en fijar los aumentos salariales en base a la inflación proyectada, de manera de no indexar los salarios, al tiempo que se postulaba un retiro gradual del Estado de la negociación salarial, una vez producido un descenso significativo delainflación, reduciendo a aquellaa la instancia bipartita, y el propósito de reglamentar el derecho dehuel ga. Esto seenmarcó en una política económica dereducción del déficit fiscal através deun plan deajusteantiinflacionario. El período que se inicia con la administración blancamarca, en estesentido, una transformación profunda en el sindicalismo decorte keynesiano, inclusivo, central izadoy al tamentepolitizado, para dar lugar a un sindicalismo "poskeynesiano" fuertemente descentralizado, fragmentario, con menor presencia en el espacio público y más despolitizado (Lanzaro, 1991).

En 1995, retorna al poder el gobierno colorado. En este nuevo período, el elenco gobernante, lejos de modificar los componentes señalados en las relaciones laboral es, tendió aintensificar la política de descentralización de la negociación. Un indicador de la continuidad con la políticaanterior es que, hasta 1999, el Ministerio de Trabajo siguió en manos del Partido Nacional. 
A nivel delanegociación colectiva, seprofundizan lastendencias reseñadas más arriba. Lanegociación por empresa se vuelve casi mayoritaria; la negociación semantienea nivel bilateral; aparecen, en los convenios, diferentes cláusulas sobre flexibilización de horarios, de cantidad de trabajadores, de condiciones salariales, etc. (Cozzano; Mazzuchi; Rodriguez, 1997). En este período, aparece con fuerza el problema del desempleo, producto delaincapacidad demuchos sectores industriales para competir en las condicionesimpuestas por laintegración regional. El desempleo industrial, a su vez, generó una debilidad crecientedel movimiento sindical en los diferentesámbitos denegociación, lo queacentuó lastendencias descentral izadorasy ladesprotección de los trabajadores, tanto industriales como del sector servicios.

\section{LOS ACTORES LABORALES: cambios y permanencias}

La desregulación y la flexibilidad, como criterios cimentadores de los diseños productivos que acompañan la modernización tecnológica, acentuaron la fragmentación de demandas y la heterogeneidad desituaciones, debilitando los referentes colectivos y declasedelos actores sociales. La negociación por empresa, la incorporación de la productividad como criterio deasignación salarial y los nuevos procesos de gestión de recursos humanos en las industrias más modernizadas generaron múltiples diferenciaciones sectorialesy por empresa, de acuerdo a desempeños y productividades asignadas por el mercado, lo que acentuó las heterogeneidades salariales, las diferencias de capacidades redistributivas, la competencia por las cal ificaciones y el desarrollo deestrategiasindividualistas al interior delasunidades productivas.

Las dimensi ones corporativas desplazaron el accionar de los partidos políticos, aunque en diferentesintonía queen épocas anteriores. Yano setrataba deun actor homogéneo queseinserta en el sistema político, proponiendo demandas colectivas, sino que se producen fuertes diferenciaciones y se acentúan heterogeneidades que particularizan las demandas, fragmentando la lógicacolectivay debilitando lasinterrelacionescon el sistema político (Lanzaro, 1991). Esto implica quelos organismos centrales delas organizaciones sindical es pasaron a adoptar actitudes defensivas y fueron cuestionados como representantes delos trabajadores en tanto sujeto político. La pérdida de centralidad y de capacidad de mediación despolitiza la función sindical y pone en relieve las adscripciones corporativas como elementos determinantes del accionar sindical, de sus formas organizativas y de sus procesos de toma de decisiones (Pucci, 2003). La capacidad deacción del sindical ismo, en especial en los países del capital ismo periférico, está vinculada con su carácter de "minoría ponderada" (Schmitter, 1974). Su poder político no estádi rectamenterel acionado con su poder numérico, sino con la ocupación de posiciones estratégicas clavesquesobredimensionan su peso como actor. La bilateralización de la negociación colectiva le quita centralidad al accionar sindical, limitando su posición estratégica y, por lo tanto, su poder.

Estastendencias apuntan aun debilitamiento del movimiento sindical, tanto en lo querespectaa su peso estructural en la economía, como a sus capacidadesdeimplementación deacciones colectivas en el escenario público. El sindicalismo, queen la primera admi nistración col orada fue muy crítico respecto a la política laboral, fue más crítico aún frente a las políticas de liberalización y de desregulación laboral. El intento dereglamentar la actividad sindical fuerechazado con éxito, pero la fijación bilateral de salarios llevó a la descentralización de la acción sindical, la fragmentación deinteresesy el predominio delos clivajes corporativos en la toma de decisiones.

La clásica actitud confrontacionista del movimiento sindical se vio contrarrestada en muchas empresas o sindicatos por una actitud más colaboracionista, aunque también se perfilaron fuertes resistenciasala modificación delas formas 
deorganización del trabajo. Los círculos decalidad, la responsabilidad del trabajador y todos los elementos quecomponen las nuevas modal idades de producción a escala mundial son aún resistidos por los trabajadores y por los sindicatos. Esto se debe, sin duda, a que estos elementos aparecen asociados, antelos trabajadores, ala desregulación de las relaciones laborales y al deterioro de las condiciones de trabajo, más que a aumentos en Iosniveles de calidad y de eficiencia en el trabajo (Pucci, 2003).

Otro elemento de cambio profundo en la orientación sindical esla priorización deladefensa del empleo como estrategiadelucha, dejando delado el énfasishistóricoen ladefensa del salario como eje delas reivindicaciones. Estecambio es producto de laamenazadedesempleoqueprovienedelaapertura económicay la pérdidadecompetitividad demuchas empresas, y del desempleo causado por larenovación tecnológica. Estecambio ambientóun acercamiento y una mejor disposición para el diálogo entre empresarios y trabajadores, aunque la perspectiva de transformaciones profundas en las relaciones laborales se mantuvo al ejada. Esta mejor actitud parael acercamiento no seaprovechó políticamente por la falta de instancias institucionales que permitieran traducir esta mejor disposición en acuerdos social es delargo al cance. Ladesregulación laboral y la prescindenciaestatal multiplicaron los focos deconflicto, en tanto los elencos gobernantes perdieron interlocutores con capacidad decentralizar y unificar la tramitación delos conflictos.

Si bien el sindicalismo se ha debilitado numéricamente y ha perdido buena parte de su peso político como actor social, han acrecentado su poder en tres planos: como referentesimbólico de la clase obrera, como actor capaz de articular movilizacionesmásamplias dela población y como referente de la realidad política y social del país (Supervielle; Quiñones, 2003). Los cambios productivos y políticos reseñados más arriba también han influido en la organización del movimiento sindical, que ha desarrollado modelos dered social en susformas defuncionamiento, más adecuadas para articular la dispersión y atomización social en lacual seencuentran laclase trabajadora y los sectores populares en general. También se han modificado los criterios de legitimidad para acceder y ejercer el poder al interior delas organizaciones sindicales. El fundamento esencialmente político del carisma sindical ha dado paso a un carisma que requiere, además de los políticos, fundamentos técnicos y capacidades de presencia en los medios y de articulación con actores externos al movimiento sindical (Supervielle; Quiñones, 2003).

Como la literatura especial izada hamostrado reiteradamente, las gremiales empresariales tienen una lógica de acción diferente a la de los movimientosobreros. Laparticipación gremial no es una condición necesaria para mantener sus ganancias, porquesu posición en la sociedad y en la producción le otorga un poder estructural que lo vuelve autónomo de la acción colectiva (Offe, 1985). Por otra parte, su acción colectiva entra en permanente tensión con sus intereses privados, en la medida en quelos gremios seconforman con empresas que compiten entre sí en el mercado. Aunqueestos efectos sean más atenuados para el caso uruguayo, dada la configuración de su estructura industrial, la participación de las empresas en la toma de decisiones y en la dirección de las organizaciones gremiales, en los pocos casos estudiados (Bruera; Riella, 1989), es relativamentebajay con tendencias a la conformación de “oligarquías internas" (Pizzorno, 1976).

Otradiferenciaen lalógica deacción colectiva delosempresarioscon respecto al movimiento sindical eslaproliferación demúltiplesorganizaciones gremiales, producto de la diversidad de intereses representados. Estafuertediferenciación permite a los empresarios multiplicar los canales de expresión de demandas, pero, al mismo tiempo, dificultala elaboración deproyectos colectivos. En este sentido, se ha señalado que los empresarios históricamentehan orientado su acción colectiva más hacia el veto de propuestas que consideran perjudiciales para sus intereses, que a la elaboración deproyectos societal es delargo aliento (Filgueira, 1988). De todas maneras, Ios 
empresarios, en nuestro país, han desarrollado históricamente estrategias corporativas, aunque sean discretas, quevan desdeuna acción tipo "grupo depresión", desdefuera delosámbitos estatales y de decisión, hasta su inclusión en formas de corporativismo organizado" desde 1933 en adelante (Caetano, 1992) Las políticas de desregulación y debilaterización dela negociación desmantelaron las formas corporativas de participación, acentuaron las tendencias históricas haciael desarrollo deacciones del tipo "grupo de presión", en tanto la negociación tendió a "privatizarse," es decir, a reducirseal ámbito privado decada empresa, sin necesidad deestablecer espacios col ectivos deacción. ${ }^{2}$

\section{EL NUEVO ESCENARIO: continuidades y rupturas}

El gobierno de izquierda que asume en el año 2005 basó su triunfo en una crítica al modelo neol iberal implementado en las últimas décadas en el país. Desdeel punto devista laboral, una de sus primeras medidas fue retomar los procedimientos denegociación colectivatripartita, real izando al gunas modificaciones de los grupos que conforman los Consejos de Sal arios e incorporandoalos trabajadores rurales y a las empleadas domésticas. Laimplementación dela negociación colectiva facilitó la organización desindicatos en muchas ramas en las quenunca hubo sindicatos fuertes, y en otras en las que el sindicalismo se había debilitado. Este proceso permitió fortalecer algunos espacios del movimiento sindical o, al menos, contrarrestar su debilidad estructural a través delos impul sos generados por la convocatoria de Consejos de Salarios. La incorporación de los trabajadores rurales a la negociación colectiva levantó un veto impuesto durantemucho tiempo por las gremiales rurales, en especial la Federación

${ }^{2}$ Es importante señalar que la acción colectiva de los gremios empresariales de nuestro país ha sido menos estudiada que la acción colectiva del movimiento sindical, por lo que el aporte que se puede realizar en ese plano es menor.
Rural, que se opusieron a cualquier forma de negociación con los trabajadores desu sector.

Estos nuevos sindicatos se han conformado, en líneas generales, con liderazgos menos politizados y con poca experiencia en la acción colectiva, en estructuras sindical es más descentralizadas y con lógicas deacción más articuladas en torno a demandas corporativas decorto plazo, en detrimento de estrategias políticas globales y de largo plazo. La situación de prescindencia estatal y de desmontaje creciente de las instancias institucionales deintermediación deintereses de los últimos quince años aumentó la posibilidad de desarrollo, en los diferentes sindicatos, de orientaciones con al to potencial conflictivo, o que, por el contrario, de actitudes anómicas, que paralizan la capacidad de incidencia de los trabajadores en las políticas públicas. Estas dos opciones, que eran un objetivo implícito de las políticas dedesregulación implementadas hastael año 2005 , no resultan funcionalesalaimplantación de un nuevo modelo productivo que requiere de la activa colaboración de las organizaciones laboralesen diferentes planos: compromiso con la calidad, mayor eficiencia, productividad, mejoramiento de la capacitación, mayor responsabilidad, disciplina y capacidad de decisión en relación a su tarea, etc. En este sentido, la convocatoriaala negociación col ectiva puede considerarse un factor positivo en el plano no sólo delas relaciones laborales sino también delas políticas de desarrol lo del país.

La prolongada ausencia de espacios de negociación colectiva puede explicar, a su vez, al gunas actitudes radical es verificadas en esteperíodo, como las ocupaciones de local es detrabajo olaintransigenciadealgunas reivindicaciones. Más alláde la acción degrupos políticos de tendencia radical, laincorporación drástica ala negociación colectiva deamplios sectores con escasatradición sindical y con escasa capacidad para generar el necesario proceso de "reducción de las áreas de igualdad" (Pizzorno, 1976) generan, a nuestro juicio, al gunos de estos "efectos perversos" en el proceso denegociación. 
Otro del os desafíos que se plantean en este nuevo escenario es cómo articular la negociación por rama, que se reinstal a en este período, con la negociación por empresa, que se extendió ampliamente a partir de los años 90 (Cozzano; Rodríguez; Mazzuchi, 2001). Esta articulación no es menor, ya que buena parte de los cambios productivos de envergadura tienen su espacio de negociación privilegi ada en la empresa. Si pensamosquela eficiencia productivapasa cada vez más por la calidad delos productos, y que, paraal canzar al tos niveles de calidad, se requieren cambios tecnológicos y de organización del trabajo que afectan la cantidad y calidad del empleo, la participación sindical anivel deempresasevuelve crucial.

Por otra parte, como hemos mostrado más arriba, los cambios productivos tienen tendenciaa acentuar la heterogeneidad interna de los trabajadores, lo quese refleja también en su lógica de negociación. Esta estructura puede incentivar, potencial mente, el desarrollo deestrategias individualistas, tanto a nivel individual como sectorial, en la negociación colectiva. En las ramas con sindicatos relativamente fuertes, el desarrollo de la negociación por empresa impuso una lógica de acción sindical quepermitió enriquecer lapauta de negociación, incorporando nuevos temas, comolos del cambio técnico, capacitación, carreraslaborales, etc., más allá de las reivindicaciones salariales. Al tiempo que enriqueció la negociación, esta lógica debilitó los espacios centrales de negociación colectiva y tendió a una fragmentación de la organización sindical, en función de lógicas más corporativas. La recuperación delanegociación por rama establece una dinámica que contrarresta las tendencias descentralizadoras, al tiempo que se pierde riqueza en el contenido de la negociación, debido a que, en estenivel, tiendegeneral mentea centrarseen el tema salarial. Una posiblesolución deestatensión es incorporar, en lanegociación por rama, temas y criterios general es como el del cambio tecnológico, capacitación, carreras profesionales, defensa del empleo, entre otros, que respalden el accionar sindical a nivel dela empresa.
En el caso del os empresarios, las diferencias de inserción en los mercados y los diferentes niveles de modernización y de eficiencia productiva, inter e intra rama, han aumentado la clásica heterogenei dad de intereses de este actor (Filgueira, 1988). Una de las preguntas que nos podemos hacer es si los empresarios prefieren la negociación por ramao lanegociación por empresa. Siguiendo a autores como Sisson (1987), la negociación por rama, al contrario de lo que muchos actores y analistas piensan, acota menos el poder del empresario que la negociación por empresa, en la medida en queseremiteexclusivamentea los salarios, dejando los demás temas a la librediscrecionalidad del empresario. Por otraparte, la negociación por rama permite controlar un aspecto dela competenciainter-empresarial anive de rama: el costo de los salarios. Estos mecanismosfuncionan como incentivosa la participación de las gremiales empresariales en la negociación colectiva por rama deactividad.

La realidad uruguaya parece desmentir estas tesis, en la medida en que el empresariado uruguayo ha preferido la negociación a nivel de empresa, antes que la negociación por rama de actividad. Esto se debea una debilidad intrínseca del sindicalismo uruguayo, producto de la estructura industrial uruguaya. Lastesis deSisson se pueden corroborar en contextos industriales desarrollados, en los cuales existen grandes empresas que nuclean fuertes contingentes de trabajadoresy dondeseestablecen los parámetros estructurales para la organización de sindicatos fuertes a ese nivel. En el caso uruguayo, con predominio de pequeñas empresas, cuando no de talleres, la fuerzadel sindical ismo estáen su acción en ámbitos públicos centrales, como los que se establecen en la negociación por rama deactividad. La capacidad de negociación de los empresarios se ve reducida en este ámbi to de negociación, lo queexplica su preferencia por la negociación por empresa.

Laconvocatoriadela negociación colectiva por rama deactividad, a partir del año 2005, obliga al empresariado a incorporarse nuevamente a 
espacios en los cuales su capacidad de acción colectiva es relativamente limitada. Esto implica queesteactor genere, en muchos casos, estrategias puramente defensivas, que se expresaron, entre otras, en la oposición a las nuevas figuras jurídicas queseimplementan por el gobierno electo.

Como resumen, si tomamos como referencia la experiencia de instalación de Consejos de Salarios en 1985, quetambién seimplementótras más de quince años de ausencia de negociación colectiva, podemos encontrar, hasta ahora, aspectos en común y aspectos claramentediferentes en relación a su impacto en los actores sociales. Los aspectos en común se pueden sintetizar en:

- impactos positivos en la reorganización del movimiento sindical en las ramas en las que históricamente tenían bajos niveles de sindicalización;

- explosión dedemandas largamentepostergadas, en al gunos casos con acciones queamenazaron la propiedad privada o el control del Estado;

- resistencias del os empresarios a partici par en la negociación col ectiva, estableciendo diferentes tipos decondiciones.

Las diferencias más importantes son las siguientes:

- aumento de la heterogeneidad interna de los actoreslabores;

- Iosniveles depolitización y dearticulación con el sistema político del actor sindical han disminuido;

- nuevas exigencias de competitividad para los empresarios, lo que le replantea a este actor la funcionalidad dela negociación colectiva.

Si consideramos quela construcción dela competitividad pasa por mejorar la calidad de la producción, introduciendo cambios tecnológicos y organizativos queincorporen los conocimientos y las habilidades de los trabajadores al proceso productivo, la estabilidad de la mano de obra pareceuna condición imprescindibledeesteproceso. En estemarco, la negociación colectiva puedeser un instrumento eficaz para la discusión detemas como los dela mejora dela cal idad, la capacitación y el desarrollo denuevas competencias laborales, además del clásico tema salarial. La recuperación delosmodelos históricos denegociación colectiva permitiríainiciar este proceso, a condición deque se revisen y profundicen los formatos construidos para actores sociales que se enfrentaban a desafíos muy diferentes a los actuales.

Lainstauración dela negociación colectiva apunta también a reforzar los mecanismos institucionalizados deintermediación deintereses, que han adolecido, históricamente, de debilidadesinstitucionales. Laimplementación dearenas denegociación estuvo, en el pasado, fuertemente subordinada a la acción de los partidos políticos, en el poder y en la oposición organizada. El fortalecimiento delos mecanismosinstitucionales denegociación col ectiva permi tequelamismafuncioney cumpla sus objetivos con independencia de las rotaciones de poder o de las diferentes al ternanciaspolíticas, apuntando alaconformación demodel os deneocorporativismo social quetomen como referencia la experiencia de negociación colectiva de buena parte de los países europeos.

\section{CONCLUSIONES}

La impronta neoliberal en la cual se desarrolló el proceso de integración regional y a partir de la cual se implementaron las políticas haciael mundo del trabajo tuvo un impacto negativo en la capaci dad de acción del sindicalismo y en los marcos institucionales en los cuales se desarrolla la negociación colectiva. Los desafíos que se le presentan al gobierno de izquierda, en este plano, son múltiples, y difícilmente pueden ser resueltos en el corto plazo. Una de las dificultades deeste proceso es poder construir un modelo derelaciones laboral es queaparezca como alternativo a la propuesta neoliberal, pero que no impliquenecesariamentela restauración demodelos que responden a la época del modelo sustitutivo deimportacionesyal estilo dedesarrollo hacia adentro delos años 50. La convocatoriaa los Consejos de Sal arios se realiza en el marco de la Ley de Consejos de Salarios que se promulgó en el año 1943, y que fuela bandera de lucha delos 
trabajadores durante el período neoliberal. Estos formatos deben ser revisados y actualizados, incorporando las necesidades que se presentan en las nuevas realidades productivas y en la actual conformación delosactores laborales. En esteplano, el nuevo gobierno ha realizado al gunos avances importantes, como la promul gación de la Ley de Fuero Sindical y la elaboración de propuestas legales queatenúen los impactos negativos delas tercerizaciones en los trabajadores.

En el plano de la reestructuración productiva, lairreversi bilidad deal gunos cambios es más evidente. La necesidad de modernizar la producción y de establecer nuevas formas de organización del trabajo, orientadas a mejorar la calidad de los productos y del trabajo, aparece como una tendencia de los mercados internacional es que va más allá de orientaciones ideológicas puntuales. Tanto empresarios como trabajadores seven enfrentadosal desafío deconstruir procesos productivos competitivosy eficientes, para lo cual se requiere la superación de inercias y el desarrollo deespacios denegociación a nivel de empresas que generen la confianza necesaria en ambas partes para apostar a procesos decambio delargo plazo.

Los procesos de modernización de la industria uruguaya están radicados fundamentalmenteen las empresas multinacionales, queno son las que tienen problemas de competitividad más acuciantes. Esta paradojarespondetambién al tipo de producción que desarrollan las empresas. LoS mercados internacional es parecen ser más exigentes en materia de calidad que el mercado interno, por lo que las empresas nacionales están menos presionadas por exigencias demodernización que las mutinacionales. Por otra parte, las exigencias normativasy estatal es delos países latinoamericanos son, en general, menores quelas delos Estados de pertenencia de las matrices de las empresas multinacionales.

Sin embargo, las necesidades de mejorar la competitividad no dejan deser dramáticas también para las empresas nacionales, por lo que la generación de estructuras de cooperación para mejorar la calidad dela producción es también una necesidad paralasmismas. Lanegociación colectiva y el desarrollo de espacios de diálogo, en el marco de las relaciones laborales, son condiciones necesarias para generar mayor confianza entre las partes, perono parecen suficientes. Laconformación denuevas formas decooperación en el seno delas empresas pareceunacondición imprescindiblepara alcanzar estos objetivos. Las empresas locales, muchas veces, no visualizan los beneficios deestos cambios, debido a queel tema decalidad no seha impuesto en el mercado uruguayo, por lo que no existe una demanda concreta, y porque, muchas veces, los costos se visual izan como superiores a los beneficios. Esta perspectiva deja de lado los cambios endógenos quelos procesos de mejora de calidad introducen en el funcionamiento interno delaempresa, independientementedelas demandas del mercado.

Para los colectivos detrabajadores, en particular para los sindicatos, establecer relaciones de confianzaimplicadesarrollar accionesen lascuales a laclásicaracionalidad estratégica seleincorporan nuevas formas de racionalidad, que, en algunos casos, obligan a postergar demandas puntuales específicas (sal arios, carreras profesionales), para incorporar su acción en una lógica gl obal de más largo plazo. En ambos casos, la construcción de formas de cooperación basadas en la confianza dependerá de la fenomenología específica que asuman las interacciones entreambas partes. LoS resultados deesta compleja relación tienen un al to nivel de contingencia, ya que dependen del tipo de interacción que se establezca, lo que pone en primer plano la necesidad de establecer cambios en las orientaciones estratégicas tradicionales de empresariosy sindicatos, paraenfrentar los desafíos que se presentan en un contexto que impone nuevas posibilidades y nuevos riesgos.

(Recebido para publicação em setembro de 2007) (Aceito em novembro de 2007) 


\section{REFERÊNCIAS}

ARGENTI, Gisela. Hacia una mejor articulación entre el trabajo y sus tecnologías: la negociación colectiva de los cambios. En: SEMINARIO LATINOAMERICANO: nuevas tecnologías e impactos en la clase trabajadora y el sindical ismo. Buenos Aires: 17 al 30 set. 1989.

BRUERA, S.; RIELLA, A. Composición de las Directivas de las Cámaras Empresariales. Documento de Trabajo n.162, Montevideo, CIESU, 1989.

CAETANO, G. Partidos, Estado y Cámaras empresariales en el Uruguay contemporáneo (1900-1991) En: CIESU. Centro de Informaciones y Estudios del Uruguay. Organizaciones empresariales y políticas públicas. Montevideo: FESUR/ICP/Ediciones TRILCE, 1992.

COZZANO, B.; MAZZUCHI, G.; RODRIGUEZ, J. M. Conflictividad laboral 1er semestre 1996 y perspectivas. Montevideo: Programa de Modernización de las Relaciones Laborales, UCUDAL, 1997.

; ROdRíGUEZ, J.M.; MAZZUCHI, G. La transformación de las relaciones laborales en Uruguay 1985-2001. Montevideo: UCUDAL, 2001.

FILGUEIRA, C. Concertación salarial y gremios empresariales en Uruguay. En: . Política económica y actores sociales. Buenos Aires: PREALC, 1988

LANZARO, J. El sindicalismo en la fase poskeynesiana Cuadernos del CLAEH, Montevideo, v.16, n.58/59, 2da. Serie, 1991.

- Las Cámaras empresariales en el sistema político uruguayo: acciones informales e inscripciones corporativas. En: CIESU. Centro de Informaciones y Estudios del Uruguay. Organizaciones empresariales y políticas públicas. Montevideo: FESUR/ICP/Ediciones TRILCE. 1992

NOVICK; M.; YOGUEL, G.; CATALANO, A.; ALBORNOZ, F. Adaptación de modelos productivos en países emergentes. El caso de la industria automotriz en la Argentina. Buenos Aires: LITTEC/UNGS, 2002.

OFFE, C. Disorganized capitalism, contemporary transformations of work and politics. Cambridge: Mrr.Press, 1985.

PIZZORNO, A. Introducción al estudio de la participación política. En: ; KAPLAN; CASTELLS. Participación y cambio socia en Ta problemática contemporánea. Buenos Aires: Ed. S.I.A.P., 1976.

PUCCI, F. Sindicatos y negociación colectiva (1985-1989). Montevideo: Ediciones CIESU, 1992.
; Sociedades de riesgo y mundo del trabajo en el Uruguay contemporáneo. En: El Uruguay desde la sociología. Integración, desigualdades sociales, trabajo y educación. Montevideo: Departamento de Sociología, F.C.S., Universidad de la República, p.255- 275. 2003.

El contexto social y productivo de la nueva normativa. En: MANTERO, Osvaldo (Coord.) Protección y promoción de la libertad sindical. Montevideo: Fundación de Cultura Universitaria, 2006.

BIANCHI, C. La incorporación de recursos humanos en los Programas de Certificación de Calidad de las empresas uruguayas. Revista de Relaciones Laborales, Montevideo, n.9, dic., 2005.

QUIÑONES, M.; ACOSTA, M.; BARROS, G. Desafíos, perspectivas y estrategias del movimiento sindical: un marco analítico. In: ; ; . Aportes para la construcción de lo colectivo. Psicología y Organización del Trabajo VII. Montevideo: Editorial Psicolibros, 2006

SCHMITTER, Ph. Still the century of corporatism. The Review of Politics, [S.I.], v.36, 1974.

SISSON, K. Los empresarios y la negociación colectiva.. Madrid: Ministerio de Trabajo y Seguridad Social, 1987. (Colección economía del trabajo)

SUPERVIELLE, M.; PUCCI, Francisco. Política de relaciones laboral es e innovaciones tecnológicas en Uruguay. El caso del sector textil. En: ARGENTI, Gisel a (Ed.). Uruguay: el debate sobre la modernización posible. Montevideo: Ediciones Banda Oriental, 1991.

Condiciones de trabajo y desregulación. Anátisis delias condiciones de trabajo en Uruguay. Anuario de Ciencias Sociales. Montevideo: Departamento de Sociología, Facultad de Ciencias Sociales/Fundación de Cultura Universitaria, 1995 (Revista arbitrada).

; . Transformaciones de las condiciones de trabajo y de las relaciones laborales en la salud privada ante los procesos de gl obalización en Uruguay. Documento de Trabajo n.31. Montevideo, Departamento de Sociología, F.C.S., 1996.

: OUIÑONES, M. La implantación de la flexibilidad en Uruguay. Documento de Trabajo n.45, Montevideo: Departamento de Sociología, Facultad deCiencias Sociales, 1999.

; Las nuevas funciones del sindicalismo en el cambio de milenio. En: PUCCI, F. El Uruguay desde la sociología. Integración, desigualdades sociales, trabajo y educación. Montevideo: Departamento de Sociología, F.C.S., Universidad de la República, 2003. 
INÉRC IAS E TRANSFORMACÕES NAS RELAÇÕES LABORAIS DO URUGUAI NO MARCO DOS PROCESSOS DE INTEGRAÇÃO REGIONAL

Francisco Pucci

Este trabalho se propõe a analisar a evolução das relações de trabalho no Uruguai, no marco dos processos de reestruturação produtiva que começaram a ser desenvolvidos a partir da constituição de mercados regionais no Cone Sul. A hipótese que sustentamos é de que as transformações no mundo do trabalho produzidas no Uruguai não podem ser atribuídas unicamente à aplicação de um modelo econômico ou social específico de desenvolvimento, mas que estão inscritas em modificações estruturais de longo prazo, associadas a mudanças nas relações sociais produzidas em escala mundial. Contudo, a social relations ocurred worldwide. evolução concreta verificada nas relações However, the concrete evolution verified de trabalho é explicada pelas característi- in labor relations is explained by the cas específicas dos processos de integração regional que se expressam na conformação do MERCOSUL.

PALAVRAS-CHAVE: MERCOSUL, reestruturação, atores, negociação, trabalho.

\section{INERTIAS AND TRANSFORMATIONS IN THE LABOR RELATIONS OF URUGUAY IN THE CORNERSTONE OF THE INTEGRATION}

Francisco Pucci

This work intends to analyze the evolution of the labor relations in Uruguay, at the cornerstone of the productive restructuring processes that began to be developed starting from the constitution
of regional markets in the Southern Cone. The hypothesis we support is that the ocurred in Uruguay cannot be attributed only to the application of an economical or social model specific to development, ut are enrolled in long term structural specific characteristics of the processes of specific characteristics of the processes of
regional integration that are expressed in the conformation of MERCOSUL.

KEYwords: MERCOSUL, restructuring, actors, negotiation, work.
INERTIES ETTRANSFORMATIONS DANS LES RELATIONS DE LABEUR EN URUGUAY A L'OCCASION DES PROCESSUS D'INTEGRATION REGIONALE

Francisco Pucci

Cette étude se propose d'analyser 'évolution des relations de travail en Uruguay, à l'occasion des processus de restructuration productive qui on commencé à se développer à partir de la constitution des marchés régionaux dans le Cône Sud. L'hypothèse que nous soutenons est que les transformations du monde du travail produites en Uruguay ne peuvent pas uniquement être attribuées à l'application d'un modèle économique ou social spécifique de développement mais qu'elles sont inscrites dans des modifications structurelles à long terme, associées à des changements dans les relations sociales produites à l'échelle mondiale. Cependant l'évolution concrète, que l'on a pu constater dans les relations de travail, s'explique par les caractéristiques spécifiques des processus d’intégration régionale mis en évidence par le MERCOSUD.

MotS-CLÉs: MERCOSUD, restructuration, acteurs, négociation, travail. 